\title{
Current Situation and Future Development of Industrial Chain Finance-An Example of State Grid
}

\author{
Zitong Huang ${ }^{1, a, *}$ and Fuyou Jiang ${ }^{2, b}$ \\ ${ }^{1}$ School of Management and Economics, Beijing Institute of Technology, Beijing 100000, China. \\ ${ }^{2}$ State Grid Sichuan Electric Power Company, Chengdu 610000, China. \\ aCdream46@163.com, b17303166@qq.com
}

Keywords: Current Situation, Future Development, Industrial Chain Finance.

\begin{abstract}
This paper introduces the connotation of industrial chain finance and the existing three development models. Considering the current situation, we put forward a development strategy system for State Grid's industrial chain finance called One One Three Three Program, which respectively represents one goal, one platform, three stages and three bases. We also provide some ideas and suggestions for the future development of State Grid's industrial chain financial business
\end{abstract}

\section{The Connotation of Industry Chain Finance}

Industrial Chain Finance is defined as a finance model that capital borrower stands on the perspective of whole industrial chain finance, take the relevant enterprises in the industrial chain as a whole, with its control on logistics, commodity flow and information flow in the industrial chain, through the comprehensive credit, to provide flexible and comprehensive financial products and financial services. Funds are effectively injected into the industrial chain, in order to promote the core enterprises in the industrial chain and upstream and downstream enterprises to establish long-term strategic synergies to enhance the competitiveness of the industrial chain. As shown in Figure 1, the core idea of the earliest supply chain finance is " $1+\mathrm{N}$ ", " 1 " refers to a core enterprise in industry or supply chain, and "N" refers to the upstream and downstream enterprises around the core enterprise and the whole member unit of supply chain.

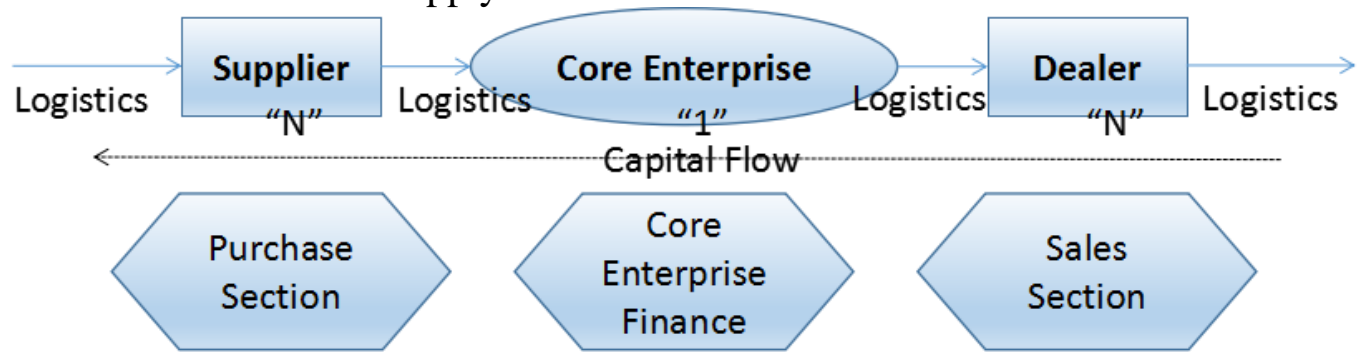

Figure 1. Concept Map Industrial Chain Finance

\section{Analysis on the Current Model of Industrial Chain Finance}

\subsection{Industrial Company Leading Model}

Industrial Company Leading Model means that core enterprise uses the detailed information they grasp of information flow, logistics, capital flow with their upstream suppliers and downstream distributors, as well as the upstream and downstream business conditions information from long-term business activities, to provide upstream and downstream enterprises with supply chain-related financial services through its subordinate commercial factoring company, financial leasing companies, small loan companies, investment and financing platform. While commercial banks or P2P platform docking core enterprises, to provide funds and other financial services for industrial company. The main representative enterprises include Alibaba Group and Haier Group. Industrial Company Leading Model is shown in Figure 2. 


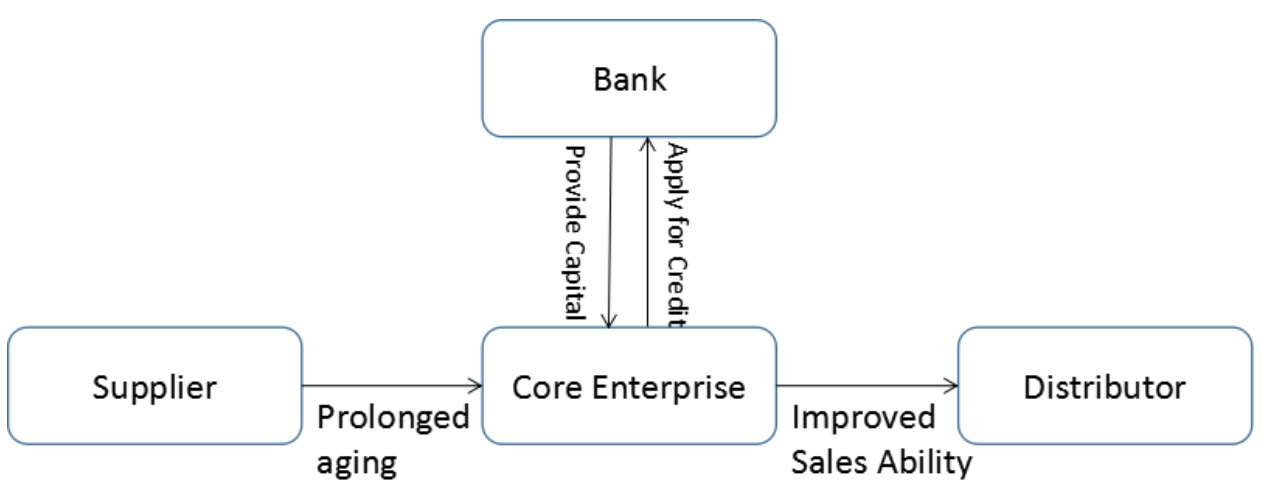

\subsection{Financial Company Leading Model}

Figure 2. Industrial Company Leading Model

Commercial Bank Leading Model is based on the real trade middle and downstream enterprises as collateral, to increase middle and small-sized company clients and expand the financial services business. In all aspects of supply chain transactions, commercial banks can design the corresponding supply chain financial model for upstream and downstream small and medium-sized enterprises according to prepayment, inventory, accounts receivable and other current assets.

In this model, with the cooperation of core enterprises, the commercial banks assume responsibility for financing project reviews and loans, and provide financial advisory, settlement, financial advisers and other financial services. Core enterprise provides credit support for upstream and downstream enterprise with its good reputation. The main representative companies include Ping an Bank, Guangdong Development Bank. Financial Company Leading Model is shown in Figure 3.

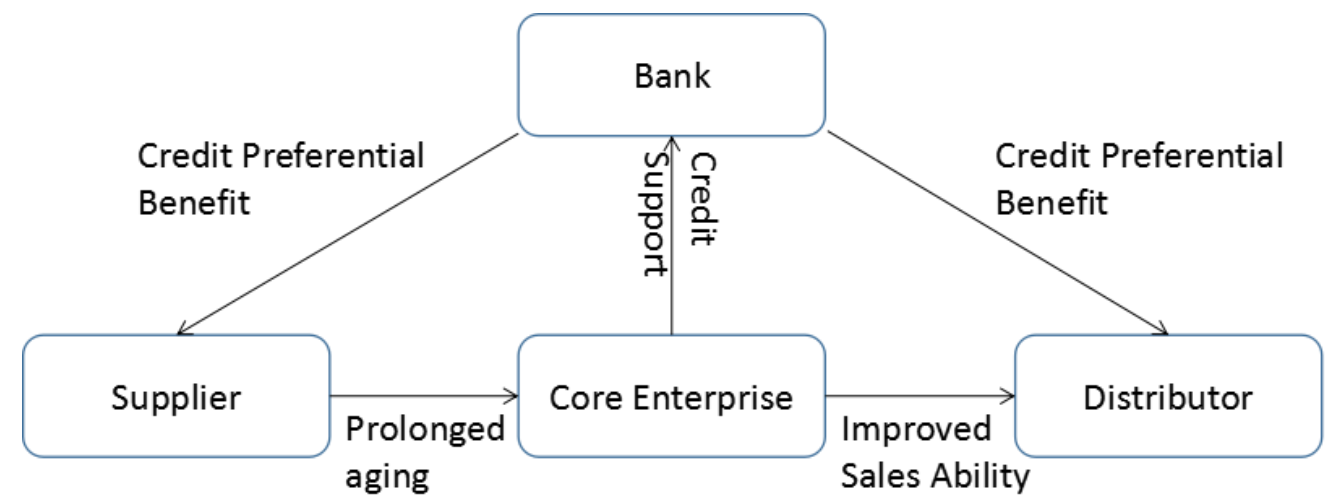

Figure 3. Financial Company Leading Model

\subsection{Third - party Professional Financial Services Company Leading Model}

Supply chain collaborative service providers include: information management services providers, supply chain financial solutions service providers, credit companies, supply chain management companies.

The supply chain cooperative service provider itself is the auxiliary party of large enterprise management and gradually establishes a good relationship of trust in the long-term business and has accumulated rich valuable business data in the system. Therefore on such basis that it can get into supply chain finance field and provides financing services and other related financial services for the upstream and downstream enterprises through the customer information advantage and industry awareness. The main representative companies include Zhongqiyun Chain Finance and Hande Information. Third - party Professional Financial Services Company Leading Model is shown in Figure 4. 


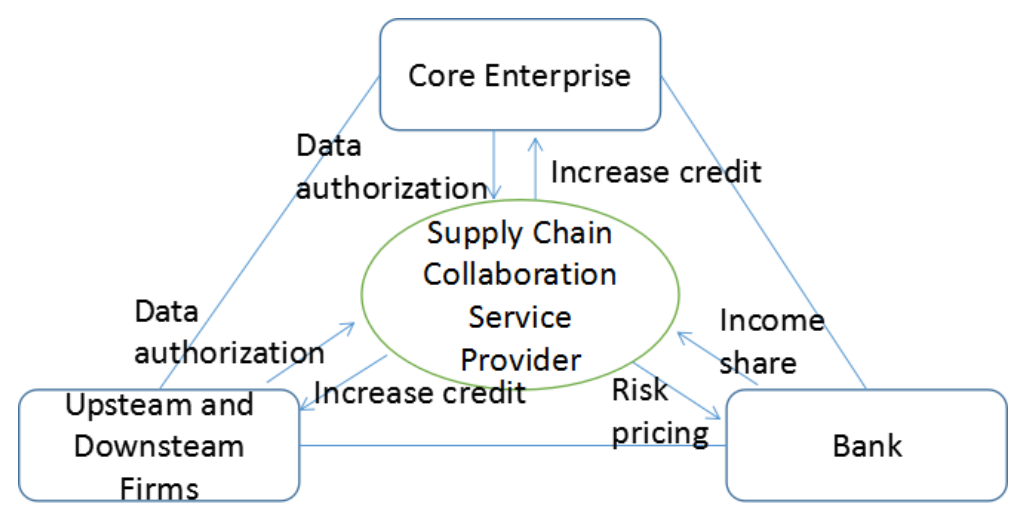

Figure 4. Third - party Professional Financial Services Company Leading Model

\section{Development stats of State Grid's Industrial Chain Finance}

Electric power is a special commodity. Electricity generators, transformers, power lines that produce, transport, distribute and consume electric connecting with electrical equipment (load) connected together form the unified power system. Electric power industry supply chain is shown in Figure 5. Its assets have unique characteristics: the amount of capital required is very large, small and medium investors are difficult to get involved; product prices are controlled by the government, although the cash flow is guaranteed, the return rate of asset is controlled by the government at the same time; the scope of business is set by the government in the form of an exclusive business area. It can be seen that the power industry is an industry with relatively stable income, growth and low liquidity.

The grid investment of State Grid is of greed demand, long industrial chain and strong driving force, which has a great driving effect on power generation, steel, aluminum, copper and other raw materials industry and electrical equipment manufacturing industry. Through the full mining and utilization of information flow, capital flow, logistics, under the premise of effective control of risk, carrying out industrial chain financial services is helpful to strengthen the strategic partnership between upstream and downstream enterprises, to promote the expansion of power grid, to strengthen the electric power industry chain competitive advantage, to consolidate the core position of State Grid Corporation in the power industry chain, and thus promote the healthy development of the entire power industry.

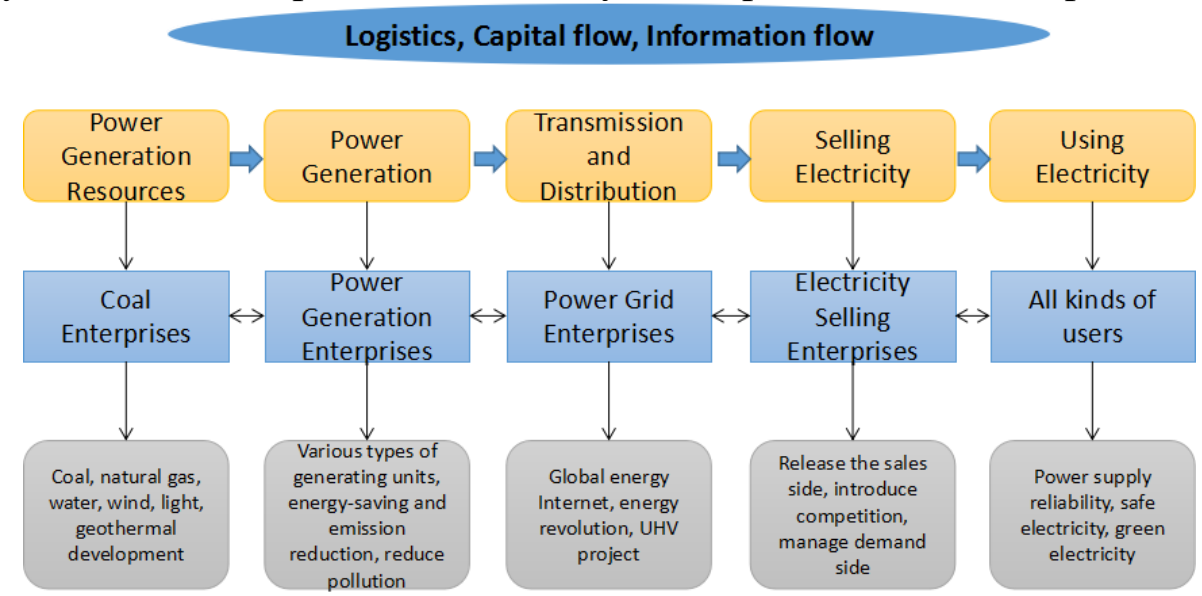

Figure 5. Electric Power Industry Supply Chain Based on "Three Streams Combined into One"

Company's industrial finance business process mainly includes three aspects: logistics, capital flow and information flow. Logistics is a physical entity, and material procurement is its core link. Capital flow refers to all activities that company's financial department participates in upstream and downstream suppliers' financial services, mainly including value-added activities. Information flow refers to the spread and flow of information brought by company's financial assets in the material procurement process, financial payment process and other stages, including the collection, processing, and transmission process. 
Among them, the capital flow is mainly achieved through financial services. Financial services determine the partial goals of every stage and co-ordinate optimization through relevant management strategies and methods. The capital flow is guided by logistics. The activities of each link in the logistics are carried out under the established objectives, and valuable information is sent to company's financial department through various types of data generated in work. The information flow will collect and process these information generated from value chain and logistics, feedback to the decision-making level of company's financial department, timely revise and improve the financial services model and methods, so that financial services goals, plans, requirements can continue to adapt to the actual production and operation of the company.

\section{The Development Strategic System of State Grid's Industrial Chain Financial Services}

The Development strategic system of State Grid's industrial chain financial services can be summarized as "One One Three Three Program". "One One Three Three Program" is based on data assets development, special products building and management model innovation, around the core of constructing industrial chain financial integrated service platform, through offline, "online offline" and "three flows combined into one" these three stages to gradually enhance the overall efficiency of the power industry chain, consolidate the core position in its own industrial chain.

"One One Three Three Program" can be expressed as one goal, one platform, three stages and three bases.

One goal is to construct an industrial chain financial integrated service platform, embed financial products into transaction chain, provide a quick and efficient way for upstream and downstream enterprises of State Grid to get financing and other services, create a combination of producing and financial model with State Grid characteristics and reference significance, further enhance the contribution rate of the financial sector on State Grid's total revenue, enhance the synergies of the power industry chain, consolidate the core position of State Grid.

One platform refers to the industrial chain financial integrated service platform, on which all kinds of financial products of different financial department can be displayed. The platform integrates both the original online platform and business of financial departments, and continues to incorporate new players and add new business categories.

Three stages means that the development process of State Grid financial services can be divided into three stages: offline, "online+offline" and "three flows combined into one". At offline stage, each financial department will carry out offline business by their own characteristics and advantages, create unique business models, explore the feasibility and business conditions of realizing online business to get preparation for online business. At "online+offline" stage, financial departments will propose online solutions against offline business' pain and difficulties, including customer information collection automation, online business application, online order and online confirmation of receivables. At "three flows combined into one" stage, with State Grid's overall deployment, Yingda Group will play the overall synergies, integrate various financial resources, and ultimately build a full-process online industrial chain financial integrated service platform.

Three bases include: developing data assets, creating specialty products, and innovating management models. First, developing data assets requires taking data as one of the most important strategic assets for State Grid's future transformation and upgrading. As the core enterprise of the industrial chain, State Grid has accumulated a lot of data on their own business, upstream and downstream enterprises, and related transactions. Second, State Grid has to create specialty products and build its own brand effect, and there are three important things: taking the financial department within system as the developing main body to build a distinctive product system in which financing products takes higher position than value-added services; introducing external market financial products as a supplement to meet the enterprise all-round, multi-level financial needs, and Yingda Group will play the functions of introducing external products and auditing; the ultimate goal of developing financial products is to achieve online operation. Third, innovating management models, 
first establish a unified and coordinated data asset management model in the company's business sector and the professional sector; then establish an operating platform, form a centralized industrial chain financial management model, sort out the industrial chain lines in the Yingda Group level to identify the unique risks of industrial chain financing for the industrial chain enterprises and provide Internet-based integrated financial solutions; and finally need to form a customer-oriented and market-oriented service system.

\section{Suggestions}

First, State Grid should grasp the power industry chain's features including resource orientation, demand-oriented, technology-intensive and capital-intensive, and take good use of complete industrial chain resource advantages. Second, State Grid should promote unity of capital flow, logistics and information flow; implement transaction, capital and logistics information synchronization; ensure that the industrial chain financial business processes timely, efficient, safe and convenient. Third, State Grid should actively promote the construction of information sector and the information platform, integrate customer information, upstream power generation enterprises, downstream power users and cross-border data, then share and release to other platforms through this information platform to support other platforms on-line operation.

\section{Acknowledgments}

The Authors thank the Young Excellent Talent Training Fund of Beijing.

\section{References}

[1]. Gonzalo Guillen. "Mariana Badell a holistic framework for short-term supply chain Management integrating production and corporate financial planning." in Production Economics, 2006, pp: 25-27.

[2]. Michael Lamoureux, "A Supply Chain Finance Prime.” in Supply Chain Finance, 2007, pp: 34-48.

[3]. Kevin Armstrong. "Building A Sound Financial Supply Chain.” in World Trade, 2006.

[4]. Hans - Christian Pfohl, Moritz Gomm. "Supply chain finance: optimizing financial flows in supply chains." in Logist. Res, 2009, pp: 149-161. 